\title{
Analogous Forecasting of Products with a Short Life Cycle
}

\author{
Natalia Szozda*
}

\begin{abstract}
Managing a supply chain for products with a short life cycle, like fashion apparel, high-tech, personal computers, toys, CD's etc., is challenging for many companies (Fisher and Raman, 1999). Because the life cycles of these products are too short for standard timeseries forecasting methods (not longer than one - two years), an important way of overcoming the challenges of managing supply chains for such products is to find appropriate forecasting methodologies. The standard forecasting methods require some historical data, which are often unavailable at the time when the forecasts are being performed for products with a short life cycle (Lin, 2005). The method described in this article allows forecasters to use life cycles of similar, analogous products to arrive at the initial forecasts for the product(s) at hand.
\end{abstract}

Keywords: short life cycle, analogous forecasting, measure of similarity, calibrating, adjusting the length.

JEL Subject Classification: C1 - mathematical and quantitative methods/econometric and statistical methods: general, C19 - other.

Revised: 09 June 2010.

\section{INTRODUCTION}

The development of the market economy has brought about changes in the ways companies function. Consumer needs are growing. There are an ever-increasing number of information sources that are constantly developing. There's more competition, more products, technological and technical advances. That is why investors, especially entrepreneurs, are forced to change the behavior of companies in the marketplace. In order to maintain their positions in the market, companies have to become more flexible. They produce fewer products and need to adjust their production to fit the demand. The supply chain is "flattened" - the product has to reach the consumer in the shortest and the fastest way possible. This shortens the period for stocking any given product. The pace of increasing the sales and withdrawing the products from the market is faster. This situation is due to the great number of novelties appearing

^ Wrocław University of Economics, Poland, natalia.szozda@ue.wroc.pl 
on the market. Despite the remarkable acceleration of the arrival of new products that compete with "old," companies are trying to maintain the quality of offered products and services. These qualities influence the interest in a given product; this interest is the definition of a product's life cycle, which usually does not last longer than two years.

Managing products with a short life cycle - like fashion apparel or technology products - is challenging for many companies. Because the life cycles of these products are too short for standard time-series forecasting methods (not longer than one-two years), one of the most important ways of overcoming the challenges of managing supply chains for such products is to find appropriate forecasting methodologies (Fisher and Raman, 1999). The standard forecasting methods require some historical data, which are often unavailable at the time when the forecasts are being performed for products with a short life cycle (Lin, 2005). The life cycle profiles for these products are different from profiles of a standard product life cycle. They have a high introduction spike, a gradual leveling-off of sales in the maturity phase, and then a swift decline in sales when a new generation of products is introduced (Wu and Aytac, 2007).

\section{LITERATURE REVIEW}

The forecasting problem of products with a short life cycle has been discussed in the literature in many different contexts. Several authors have used data-dependent forecasting methods: Harpaz, Lee and Winkler (1982), Azoury (1985), Duncan, Gorr and Szczypula (2001) use the Bayesian demand model. Johnson and Thompson (1975) and Ray (1982) model demand as an ARIMA process, Miller (1986) as an exponential smoothing formula. But we always have to remember that it is a forecast for a new product that we are after, and because of that have data from a limited period of time only or no data at all. This reality very often disqualifies statistics from these methods when trying to forecast sales for short life cycle products. New product forecasting is more than a technique: it is a process that needs to be properly managed (Kahn, 2006). The same is true for products with a short life cycle.

Some authors make entire life-cycle procurement decisions before any demand is realized or forecast updated. Kurawarwala and Matsuo (1995), Lin (2005) use the growth model. Fisher and Raman $(1996,1999)$ use heuristic methods in the field of Strategy Accurate Response. They suggest using the knowledge of experts to calculate forecasts for a new product, combining results and then deriving the most probable forecasts. Green and Armstrong (2007) describe an analogous system. This procedure involves five steps: describing the target situation, selecting experts, identifying and describing analogies, rating similarity, and at the end, deriving forecasts. Kahn (2002) suggests forecasting practices for new products during the commercialization stage, while Burruss and Kuettner (2002/2003) use forecasting by analogy before any demand is realized.

The concept of applying analogies has been explored not only in forecasting but also in many research fields, for example, in psychology, artificial intelligence and decision support. In psychology, it is termed 'pattern matching', and is found to be a basic component of many human cognitive models (Brzeziński et al. 1997) (Lindsay 
and Norman, 1977). In artificial intelligence, it is known as Case-based Reasoning (Lee and Goodwin, 2007). Nikolopoulos, Goodwin, Patelis, and Assimakopoulos (2007) used it to forecast TV audience ratings (in this application the process was referred to as 'nearest neighbor analysis'). Very often forecast by analogy is used to adjust statistical forecast in order to take into account special events (Lee, Goodwin, 2007).

In this article we present a forecasting model that can be applied when the sales history of products with a short life cycle are known for only a limited period of time. This model joins analogous forecasting with marketing. It could be used as an updated model. It helps companies compare sales of a new product with sales of similar products introduced earlier into the marketplace.

\section{ANALOGOUS FORECASTING AND MEASURES OF SIMILARITY FOR TWO FUNCTIONS}

Analogous forecasting is an efficient planning tool for products with a short life cycle from the same range of products. Analogous forecasting is defined as: "forecasting the future of a given variable by using information about other variables, with similar but not simultane-ous changes of time" (Cieślak et al. 2000).

Preparing a sales forecast by analogy requires finding analogies among variables, which is possible using measures of similarity of functions that enable stating whether sales quantities of compared products are similar. The measure of similarity described by Cieślak and Jasiński (1997) is remarkable. It is used for checking the similarity of the shape of compared objects.

It is applied in the following conditions:

(a) when functions $f$ and $g$ are given,

(b) when functions $f$ and $g$ are analyzed in ranges $[a, b]$ and $[c, d]$ then $b-a=d-c$,

(c) in the range $[a, b]$ points $a \leqslant a_{1} \leqslant \cdots \leqslant a_{n} \leqslant b$ are analyzed, and in the range $[c, d]$ points $c \leqslant c_{1} \leqslant \cdots \leqslant c_{n} \leqslant d$ are analyzed,

(d) we distinguish pairs of lines going through points $\left\{a_{i}, f\left(a_{i}\right)\right\}$ and $\left\{a_{i}+\right.$ $\left.1, f\left(a_{i}+1\right)\right\}$ and $\left\{c_{i}, g\left(c_{i}\right)\right\}$ and $\left\{c_{i}+1, g\left(c_{i}+1\right)\right\}$,

(e) $\alpha_{i}$ is a measure of the angle created by two lines described in (d).

$$
m_{i}= \begin{cases}1-\frac{2}{\pi} \alpha_{i} & \text { when functions } f \text { and } g \text { have the same } \\ -\frac{\alpha_{i}}{\pi} & \text { monotonicity, } \\ \text { when functions } f \text { and } g \text { have different } \\ \text { monotonicities. }\end{cases}
$$

A similarity measure of functions $f$ and $g$ is determined by:

$$
m=\frac{1}{n} \sum_{i=1}^{n} m_{i}
$$


It can be proved that: $-1<m \leqslant 1$.

The measure of angle $\alpha_{i}$ between lines going through specified points can be determined using one of the following formulas (Nowak et al. 1998):

$$
\cos \alpha_{i}=\frac{\left(a_{i+1}-a_{i}\right)\left(c_{i+1}-c_{i}\right)+\left(f\left(a_{i+1}\right)-f\left(a_{i}\right)\right)\left(g\left(c_{i+1}\right)-g\left(c_{i}\right)\right)}{\left.\sqrt{\left(\left(a_{i+1}-a_{i}\right)^{2}+\left(f\left(a_{i+1}\right)-f\left(a_{i}\right)\right)^{2}\right.}\right) \sqrt{\left(\left(c_{i+1}-c_{i}\right)^{2}+\left(g\left(c_{i+1}\right)-g\left(c_{i}\right)\right)^{2}\right)}}
$$

or

$$
\operatorname{tg} \alpha_{i}=\frac{\left(\frac{f\left(a_{i+1}\right)-f\left(a_{i}\right)}{a_{i+1}-a_{i}}\right)-\left(\frac{g\left(c_{i+1}\right)-g\left(c_{i}\right)}{c_{i+1}-c_{i}}\right)}{1+\left(\frac{f\left(a_{i+1}\right)-f\left(a_{i}\right)}{a_{i+1}-a_{i}}\right)\left(\frac{g\left(c_{i+1}\right)-g\left(c_{i}\right)}{c_{i+1}-c_{i}}\right)}
$$

Positive values of measure mean that both series have similar shapes (with, for example, increasing or decreasing trends), negative values - mean the opposite. The closer the value of measure is to 1 , the greater the similarity (Diettmann 2002).

The second similarity measure of compared products used in this article is Euclid Distance. It is used for checking the similarity of the value of compared objects.

\section{TRANSFORMATION THE SALES SERIES OF SIMILAR PRODUCTS}

When a product is introduced onto the market the following situation can be observed: a sum of sales quantity and the length of the life cycle of these products resemble a sum of sales quantity and a length of the life cycle of different products which were earlier introduced onto the market (Wu and Aytac, 2007). This phenomenon is shown in the Figure 1.

The shift of sales of product B backwards by 23 units (weeks) allows the observation of similarities in the life cycles of two products: A and B.

With this information about the initial sales of a new product, an analogous forecast can be calculated. We can calculate the similarity of a new product with analogous products introduced earlier to the market and chose a product that has the highest similarity in terms of sales figures.

In order to achieve a comparison as accurate as possible, we can modify the sales figures of the product introduced earlier to the market by: calibrating and/or adjusting the length of the figures being compared. Calibrating the figures changes the volume of sales being compared; while adjusting the length changes the amount of time being compared. 


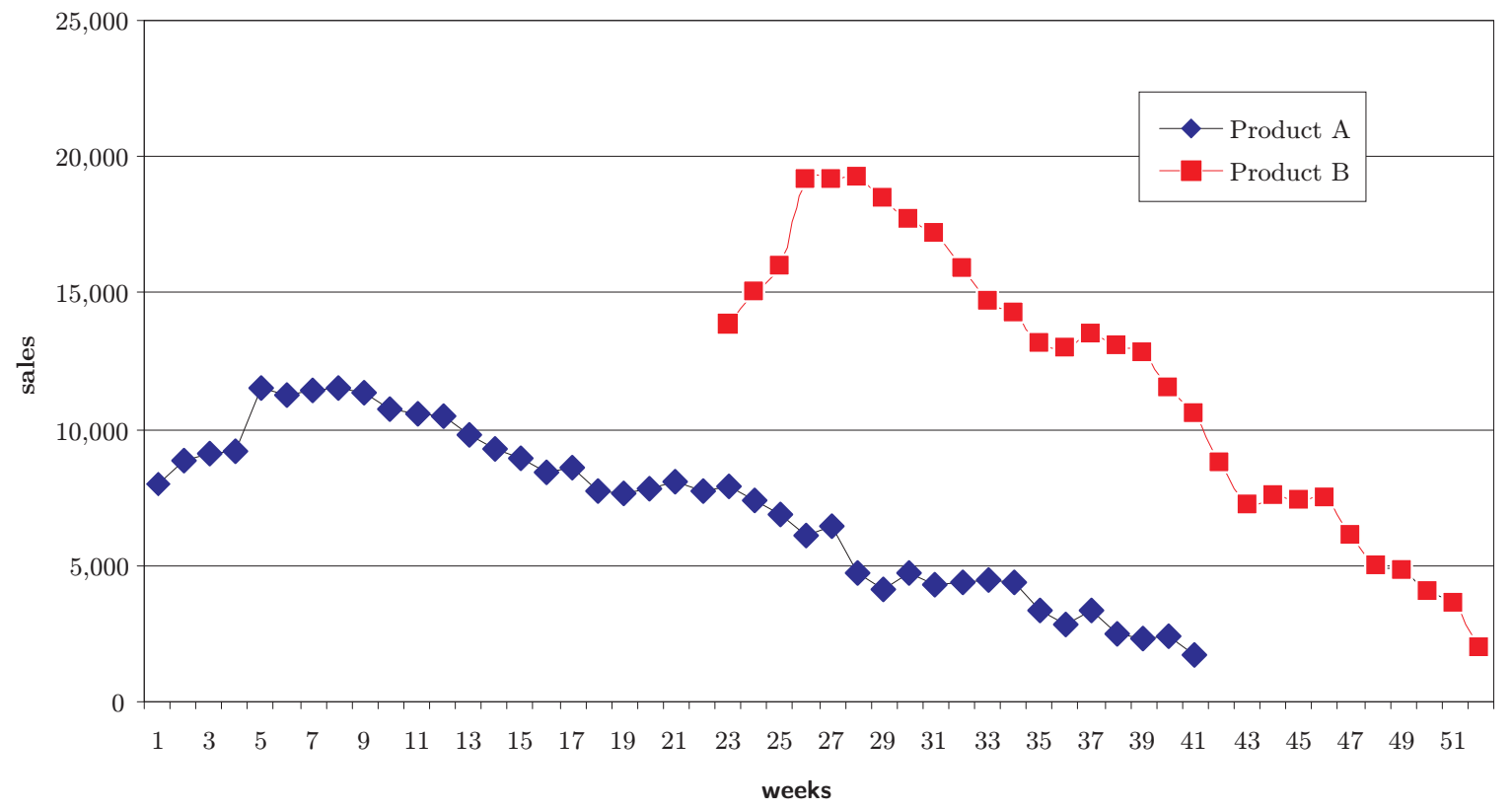

Fig. 1. Life cycles of products $A$ and $B$

\section{Calibrating}

Because sales of a new product could have a lower or higher volume than sales of sim-ilar products, those sales may need to be calibrated up or down. In this way the volumes of compared figures are adjusted.

Calibrating is done by applying the following procedure:

- Sales quantities $D_{1}, \ldots, D_{k}$ are given.

- Calibrating coefficient $w$ is calculated.

- Calibrated volumes equal: $v_{1}, \ldots, v_{k}$ :

$$
\nu_{k}=w \cdot D_{k}
$$

The value $w$ is calculated to get a comparable volume for the analyzed time period. The calibrating coefficient can be either lower or higher than 1, with the assumption that $w>0$.

\section{Adjusting the length}

The length of time being compared can also be adjusted. The sales increase of a new product can be faster or slower over time when compared with a product that was introduced earlier onto the market. In either of these circumstances the range of one product being compared is changed. 
Under this hypothesis one unit of time can be compared with a different, but analogous, unit of time. The matching parameter $\delta$ is used to transform the set of sales figures of similar products.

Adjusting the length is done by applying the following procedure:

a) $\delta<1$

- Sales quantities $D_{1}, D_{2}, D_{3}$ are given.

- The matching parameter $\delta=0.75$ is given as a part of unit of time.

- Aggregated volumes equal $e_{1}, \ldots, e_{4}$.

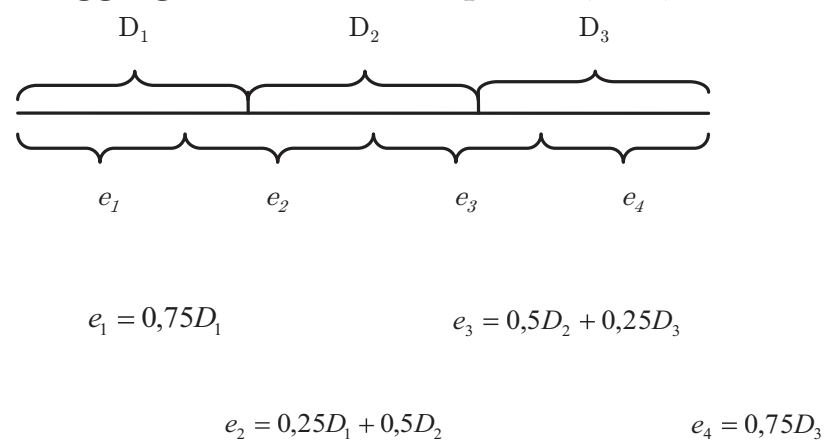

b) $\delta>1$

- Sales quantities $D_{1}, \ldots, D_{5}$ are given.

- The matching parameter $\delta=0,75$ is given as a multiplication factor of unit of time.

- Aggregated volumes equal $e_{1}, \ldots, e_{4}$.

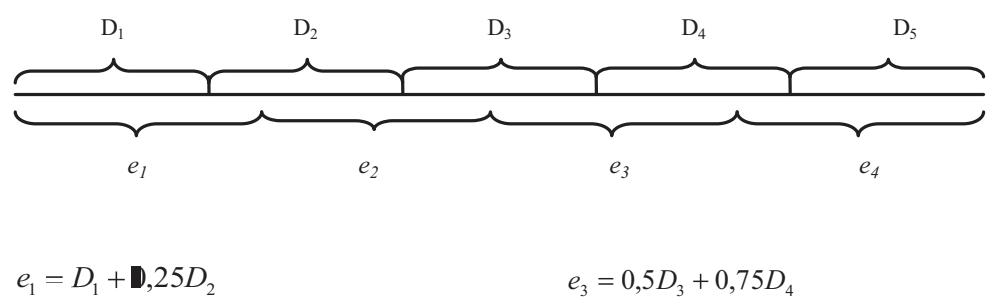

$$
e_{2}=0,75 D_{2}+0,5 D_{3}
$$

Adjusting the length is done in order to lengthen or shorten the length of series representing sales over time of similar products. If the matching parameter is greater than 1 the length of time is shortened. If the matching parameter is less than 1 the length of time is made longer.

\section{CALCULATING A FORECAST FOR A NEW PRODUCT}

Analogous forecasting for a new product using similarities between comparable objects is possible when both the sales volumes of similar products (introduced earlier to the market) and initial sales figures for the new products are available. The Measure of Similarity by Cieślak, Jasiński and the Euclid Distance are used for this procedure. We check which sales of similar products have the highest similarity to the sales of 
the new product. The next step checks if calibrating or adjusting the length of the sales of the similar products improves similarity.

The steps leading to the final result, which is the forecasting of sales of the new product are presented below:

Sales volumes for products A and B are known, as historical data have been provided. Product $\mathrm{C}$ is a new product. The goal of this research is to answer the following question: Will sales of product $\mathrm{C}$ be more similar to the sales of product A or B? If the measure of similarity is acceptable, it will be possible to create a template to be used to calculate a forecast of sales for the new product $\mathrm{C}$. If it is unacceptable, it will be necessary to check if calibrating or adjusting the length will increase the similarity between comparable time series.

\section{Calibrating}

Sales data of product $\mathrm{A}\left(a_{1}, \ldots, a_{n+k}\right)$ and $\mathrm{C}$ in time series $n+1, \ldots, n+k, \mathrm{C}$ $\left(c_{1}, \ldots, c_{k}\right)$ are given.

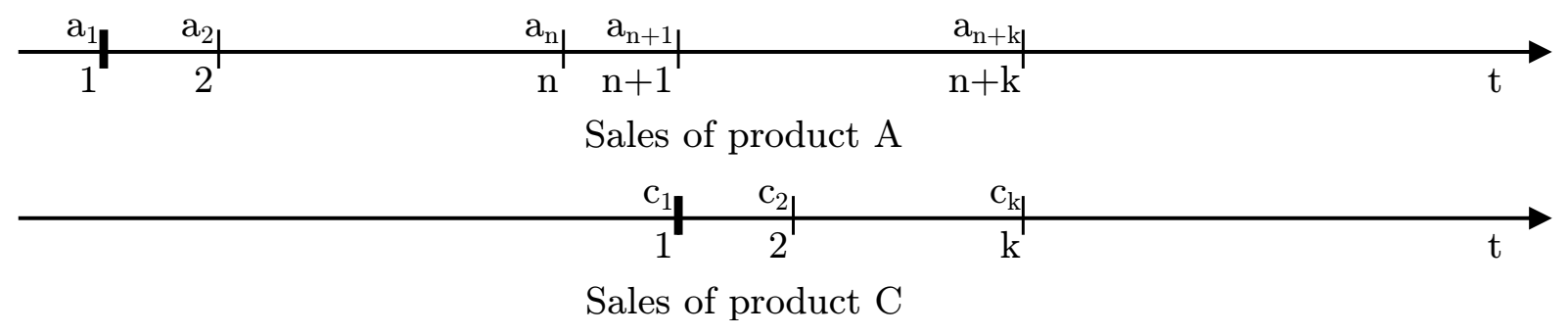

Sales data for products $\mathrm{A}$ and $\mathrm{C}\left(\left(a_{1}, \ldots, a_{k}\right)\right.$ and $\left(c_{1}, \ldots, c-k\right)$ for $\left.k>2\right)$ in first $k$ time series is analyzed. In the first step of the analysis, calibrating coefficient $w_{k}$ for every $k$ is searched. It allows a change from time series $\left(a_{1}, \ldots, a_{k}\right)$ into time series $\left(v_{1}, \ldots, v_{k}\right)$ :

$$
v_{i}=w_{k} \cdot a_{i}, \quad \text { with } i=1, \ldots, k .
$$

so as to calculate the similarity between sales of product $\mathrm{A}$ and $\mathrm{C}$ using function:

$$
f_{k}=\frac{d_{k}^{(e)}}{m_{k}}
$$

where:

$m_{k}$ - measure of similarity of both functions defined in (1) and (2),

$d_{k}^{(e)}-$ Euclid Distance defined by:

$$
d_{k}^{(e)}=\frac{\sum_{i=2}^{k} \sqrt{\left(c_{i-1}-v_{i-1}\right)^{2}+\left(c_{i}-v_{i}\right)^{2}}}{k-1}
$$

Calibrating coefficient $w_{k}^{*}$ is searched for:

$$
f_{k} \rightarrow \min
$$


Calculated calibrating coefficient $w_{k}^{*}$ is used to determine the sales forecast for product C for $k+1, \ldots, k+n$ periods:

$$
p_{k+i}=\hat{v}_{k+i}=w_{k}^{*} \cdot a_{k+i}, \quad \text { with } i=1, \ldots, n .
$$

\section{Adjusting the length}

The second step is done in order to check the possibility of calculating a more accurate similarity between volumes of sales for products $\mathrm{A}$ and $\mathrm{C}$, by using adjusting the length me-thodology. The basics of this adjustment are: modifying the time series for product $\mathrm{A}\left(v_{1}, \ldots, v_{k}\right)$ and the time series for product $\mathrm{C}\left(c_{1}, \ldots, c_{k}\right)$.

For time series $\left(v_{1}, \ldots, v_{k}\right)$ the matching parameter $\delta_{k}$, and transformation of the time series $\left(v_{1}, \ldots, v_{k}\right)$ into time series $\left(e_{1}, \ldots, e_{r}\right)$ when $r \geqslant k$, are calculated. To calculate the forecast time series, $\left(e_{1}, \ldots, e_{k}\right)$ and $\left(c_{1}, \ldots, c_{k}\right)$ are needed. Similarity is calculated by function $f_{k}$ defined by formula (7). Quantity of matching parameter $\delta_{k}^{*}$ is searched for:

$$
f_{k} \rightarrow \min
$$

When $\delta_{k}^{*} \neq 1$ the modified forecast for product $\mathrm{C}$ can be calculated. It is possible when time series $\left(v_{1}, \ldots, v_{k+n}\right)$ is transformed into time series $\left(e_{1}, \ldots, e_{k+n}\right)$ by using matching parameter $\delta_{k}^{*}$. The forecast is defined:

$$
p_{k+i}=e_{k+i}, \quad \text { with } i=1, \ldots, n .
$$

\section{Comparison of results}

The same procedure (shown in I and II) is used for product B, and the similarity between sales of products $\mathrm{B}$ and $\mathrm{C}$ is calculated.

Received similarities are compared (between $\mathrm{A}$ and $\mathrm{C}$ or $\mathrm{B}$ and $\mathrm{C}$ ) - the results for volume functions $f_{k}$ are compared and the template with the lowest $f_{k}$ is chosen.

Verification of results is done by calculating the forecast error for example MSE. For products with a short life cycle, forecasting is calculated for short periods. Thus, the following formula should be used:

$$
M S E=\frac{\sum_{k=1}^{n}\left(y_{k}-p_{k}\right)^{2}}{n-1}
$$

\section{EXAMPLE}

The example presented below illustrates the application of the methodology to calculate a forecast for a new product. Sales volumes for similar products sold on different European markets (at the beginning of their life cycles) are known. Product $\mathrm{Y}$ is introduced onto the Polish market, and it is in the same range of products. Sales volume in two quarters of the year 2008 for the new product are known. A forecast 
for Poland in the third and fourth quarters of the year 2008 is calculated by using sales of similar products. Tables 1 and 2 represent sales of analyzed products.

Table 1. Sales quantity for similar products on different markets [thousand of pieces]

\begin{tabular}{|c|c|c|c|c|}
\hline \multirow{2}{*}{ Country } & \multicolumn{4}{|c|}{ the first year } \\
\hline & $1^{\text {st }}$ quarter & $2^{\text {nd }}$ quarter & $3^{\text {rd }}$ quarter & $4^{\text {th }}$ quarter \\
\hline Holland & 442,176 & 83,702 & 263,434 & 271,300 \\
\hline Denmark & 90,173 & 60,000 & 66,244 & 136,627 \\
\hline Finland & 122,050 & 42,000 & 79,836 & 197,164 \\
\hline Sweden & 6,754 & 44,400 & 211,897 & 275,729 \\
\hline Belgium & 136,030 & 58,000 & 33,470 & 118,763 \\
\hline France & 990,010 & 656,000 & 604,000 & $1,030,400$ \\
\hline England & $1,008,619$ & 853,283 & 898,552 & 967,81 \\
\hline Luxemburg & 11,289 & 0,000 & 25,117 & 16,146 \\
\hline Estonia & 14,319 & 3,300 & 11,000 & 10,605 \\
\hline Spain & 282,099 & 564,157 & 293,200 & 460,651 \\
\hline Portugal & 94,658 & 58,000 & 133,532 & 24,909 \\
\hline Austria & 181,825 & 55,900 & 108,230 & 57,407 \\
\hline Italy & 526,257 & 211,000 & 444,270 & 828,279 \\
\hline Germany & 624,856 & 351,567 & 532,753 & 2295,35 \\
\hline Slovenia & 13,839 & 2,700 & 35,557 & 1,586 \\
\hline Ireland & 17,132 & 16,100 & 35,600 & 59,834 \\
\hline Lithuania & 28,110 & 13,458 & 26,674 & 36,763 \\
\hline Hungary & 32,483 & 38,231 & 11,131 & 117,133 \\
\hline Czech Republic & 19,049 & 43,659 & 87,95 & 173,141 \\
\hline Latvia & 3,000 & 3,000 & 1,000 & 37,415 \\
\hline Slovakia & 9,800 & 2,500 & 37,800 & 21,500 \\
\hline Greece & 22,343 & 21,400 & 15,915 & 48,503 \\
\hline
\end{tabular}

Table 2. Sales quantities of the year 2008 for a new product in Poland [thousand of pieces]

\begin{tabular}{lcc}
\hline Country & $1^{\text {st }}$ quarter & $2^{\text {nd }}$ quarter \\
\hline Poland & 201,266 & 140,800 \\
\hline
\end{tabular}

The first two quarters in sales of the new product are compared with and sales of similar products. The first transformation applied is calibrating. The best results will be obtained calibrating the coefficient with the lowest value function. 
Table 3 presents a transformation for the time series of similar products, which is the base of the forecast for the new product.

Table 3. Calibrating sales series for similar products

\begin{tabular}{lrrrrrr}
\hline Country & $\begin{array}{c}w_{k}-\text { calibrating } \\
\text { coefficient }\end{array}$ & \multicolumn{2}{c}{$\nu_{k}-$ modified sales [thousand of pcs.] } & $\begin{array}{c}f_{k}-\text { value } \\
\text { function }\end{array}$ \\
\hline Holland & 0.50 & 219,873 & 41,621 & 130,993 & 134,905 & 101.62 \\
Denmark & $\mathbf{2 . 2 7}$ & $\mathbf{2 0 4 , 4 3 8}$ & $\mathbf{1 3 6 , 0 3 1}$ & $\mathbf{1 5 0 , 1 8 7}$ & $\mathbf{3 0 9 , 7 5 7}$ & $\mathbf{5 . 7 3}$ \\
Finland & 1.83 & 223,198 & 76,807 & 145,999 & 360,561 & 68.07 \\
Sweden & 0.86 & 5,818 & 38,244 & 182,518 & 237,500 & $14,632.13$ \\
Belgium & 1.63 & 221,054 & 94,252 & 54,390 & 192,995 & 50.86 \\
France & $\mathbf{0 . 2 1}$ & $\mathbf{2 0 4 , 6 8 9}$ & $\mathbf{1 3 5 , 6 3 1}$ & $\mathbf{1 2 4 , 8 8 0}$ & $\mathbf{2 1 3 , 0 4 0}$ & $\mathbf{6 . 2 1}$ \\
England & 0.19 & 186,770 & 158,006 & 166,389 & 179,214 & 22.76 \\
Luxemburg & 17.80 & 200,951 & 0,000 & 447,098 & 287,409 & 141.84 \\
Estonia & 15.49 & 221,792 & 51,115 & 170,383 & 164,264 & 92.63 \\
Spain & 0.29 & 80,696 & 161,380 & 83,871 & 131,771 & $13,275.65$ \\
Portugal & $2, .21$ & 209,046 & 128,089 & 294,897 & 55,010 & 14.94 \\
Austria & 1.23 & 223,338 & 68,663 & 132,940 & 70,514 & 75.93 \\
Italy & 0.42 & 221,969 & 88,997 & 187,387 & 349,358 & 56.11 \\
Germany & 0.34 & 213,030 & 119,858 & 181,630 & 782,545 & 24.11 \\
Slovenia & 15.91 & 220,192 & 42,960 & 565,745 & 25,235 & 100.35 \\
Ireland & 10.35 & 177,372 & 166,688 & 368,577 & 619,478 & 37.04 \\
Lithuania & 7.77 & 218,542 & 104,629 & 207,378 & 285,815 & 40.28 \\
Hungary & 4.49 & 145,744 & 171,534 & 49,942 & 525,551 & $3,603.90$ \\
Czech Republic & 0.00 & 0,013 & 0,029 & 0,059 & 0,116 & 490.95 \\
Latvia & 57.01 & 171,033 & 171,033 & 57,011 & $2,133,067$ & $4,264.62$ \\
Slovakia & 22.71 & 222,570 & 56,778 & 858,483 & 488,291 & 87.26 \\
Greece & 7.86 & 175,686 & 168,271 & 125,142 & 381,385 & 40.57 \\
\hline & & & & & &
\end{tabular}

The best results for the value functions are obtained when sales for a new product introduced onto the Polish market are compared with sales of a similar product in Denmark. Very similar results were calculated for France. The profile of sales in those two countries are the most similar to the profile of sales for product $\mathrm{Y}$ in Poland. Using calibrating it is possible to calculate a forecast $p_{k+1}^{(w)}$, with a value of 150,187 pieces, and $p_{k+2}^{(w)}$, with a value of 309,757 pieces. The results of calibrating are shown in Figure 2.

Sales figures in Sweden, Spain, Hungary, Czech Republic and Latvia are very different from the sales figures of a new product in Poland. Sales in these countries have a very high value function. This is the reason why these product figures are eliminated from the next step. The next step is checking if adjusting the length improves the result. Outcomes of adjusting the length of time series for similar products are presented in Table 4. 


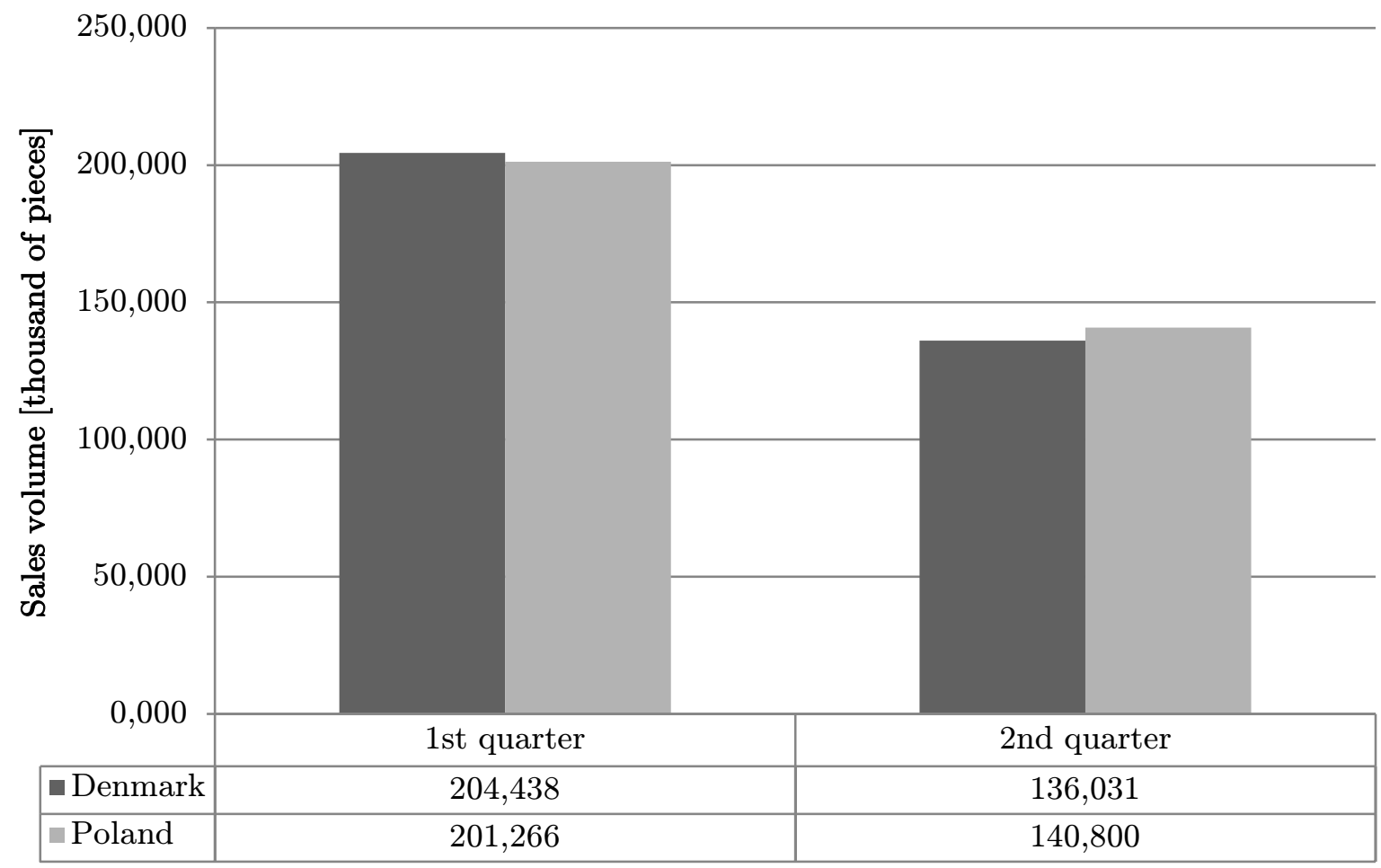

Fig. 2. Sales volume of a new product $Y$ on the Polish and modified sales of similar product on the Danish market

Table 4. Adjusting the length of sales series for similar products

\begin{tabular}{lrrrrrr}
\hline Country & $\begin{array}{c}\delta_{k}-\text { matching } \\
\text { parameter }\end{array}$ & \multicolumn{2}{c}{$e_{k}$ - modified sales } & [thousand of pcs.] & $\begin{array}{c}f_{k}-\text { value } \\
\text { function }\end{array}$ \\
\hline Holland & 1.30 & 232,360 & 130,243 & 223,596 & 203,193 & 32.98 \\
Denmark & $\mathbf{1 . 0 2}$ & $\mathbf{2 0 2 , 3 9 4}$ & $\mathbf{1 3 5 , 3 5 4}$ & $\mathbf{1 4 5 , 0 8 0}$ & $\mathbf{2 9 4 , 9 9 0}$ & $\mathbf{4 . 8 1}$ \\
Finland & 1.40 & 253,920 & 144,464 & 400,975 & 290,726 & 53.03 \\
Belgium & 0.70 & 198,949 & 97,507 & 66,518 & 165,408 & 43.54 \\
France & $\mathbf{0 . 9 9}$ & $\mathbf{2 0 2 , 6 4 2}$ & $\mathbf{1 3 4 , 9 6 5}$ & $\mathbf{1 , 3 6 9 , 3 3 0}$ & $\mathbf{2 3 0 , 7 6 6}$ & $\mathbf{6 . 0 0}$ \\
England & 1.00 & 186,770 & 158,006 & 166,389 & 179,214 & 22.76 \\
Luxemburg & 1.30 & 200,951 & 125,547 & 204,756 & 189,542 & 15.29 \\
Estonia & 1.30 & 242,238 & 166,975 & 233,137 & 139,184 & 48.72 \\
Portugal & 1.00 & 209,046 & 128,089 & 294,897 & 55,010 & 14.94 \\
Austria & 1.30 & 243,937 & 127,828 & 116,639 & 81,355 & 44.83 \\
Italy & 1.10 & 230,868 & 117,575 & 254,717 & 403,895 & 37.81 \\
Germany & 1.10 & 225,016 & 144,199 & 380,067 & 946,220 & 24.06 \\
Slovenia & 1.10 & 224,487 & 151,813 & 460,167 & 27,663 & 25.75 \\
Ireland & 1.00 & 177,372 & 166,688 & 368,577 & 619,478 & 37.04 \\
Lithuania & 1.10 & 229,005 & 135,642 & 251,646 & 335,699 & 28.32 \\
Slovakia & 0.80 & 178,060 & 78,58071 & 366,104 & 612,7478 & 66.68 \\
Greece & 1.10 & 192,513 & 176,472 & 214,529 & 484,881 & 37.82 \\
\hline
\end{tabular}


The results of value function $f_{k}$ are again lowest for the Danish market. Using matching parameter $\delta_{k}$ which equals 0,96 , the value function $f_{k}$ is calculated and equals 4,81 , which is a better result than in calibrating. Sales forecast $p_{k+1}^{(\delta)}$ and $p_{k+2}^{(\delta)}$ are changed and equal 145,080 and 294,990 pieces respectively.

The result of adjusting the length is demonstrated in Figure 3.

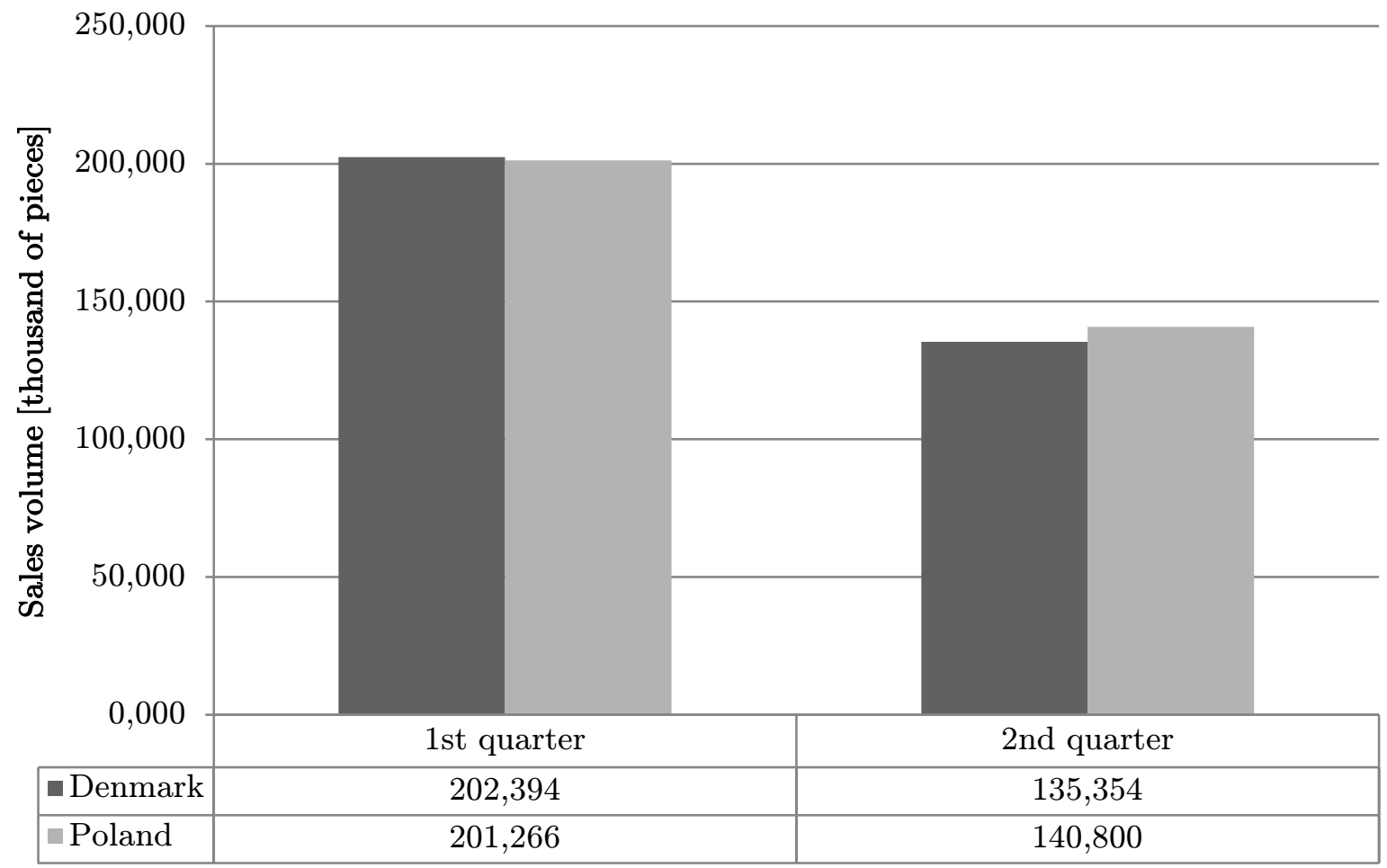

Fig. 3. Sales volume of new product $Y$ on the Polish market compared to a similar product on the Danish market after adjusting the length of time for sales being compared

A very good result was also obtained after comparing our product with a similar product introduced into the French market. But our forecast is based on the modified sales of a similar product introduced into the Danish market.

Summary of the analysis is presented in Table 5 and Figure 4.

Table 5. Comparison of sales forecasts for product $Y$ [thousand of pieces]

\begin{tabular}{crrr}
\hline $\mathrm{I}$ & 1 & 2 & $\mathrm{MSE}$ \\
\hline$y_{k+i}$ & 146,901 & 265,128 & \\
$p_{k+1}^{(w)}$ & 150,187 & 309,757 & 2002,582 \\
$p_{k+1}^{(\delta)}$ & 145,080 & 294,990 & 895,075 \\
\hline
\end{tabular}




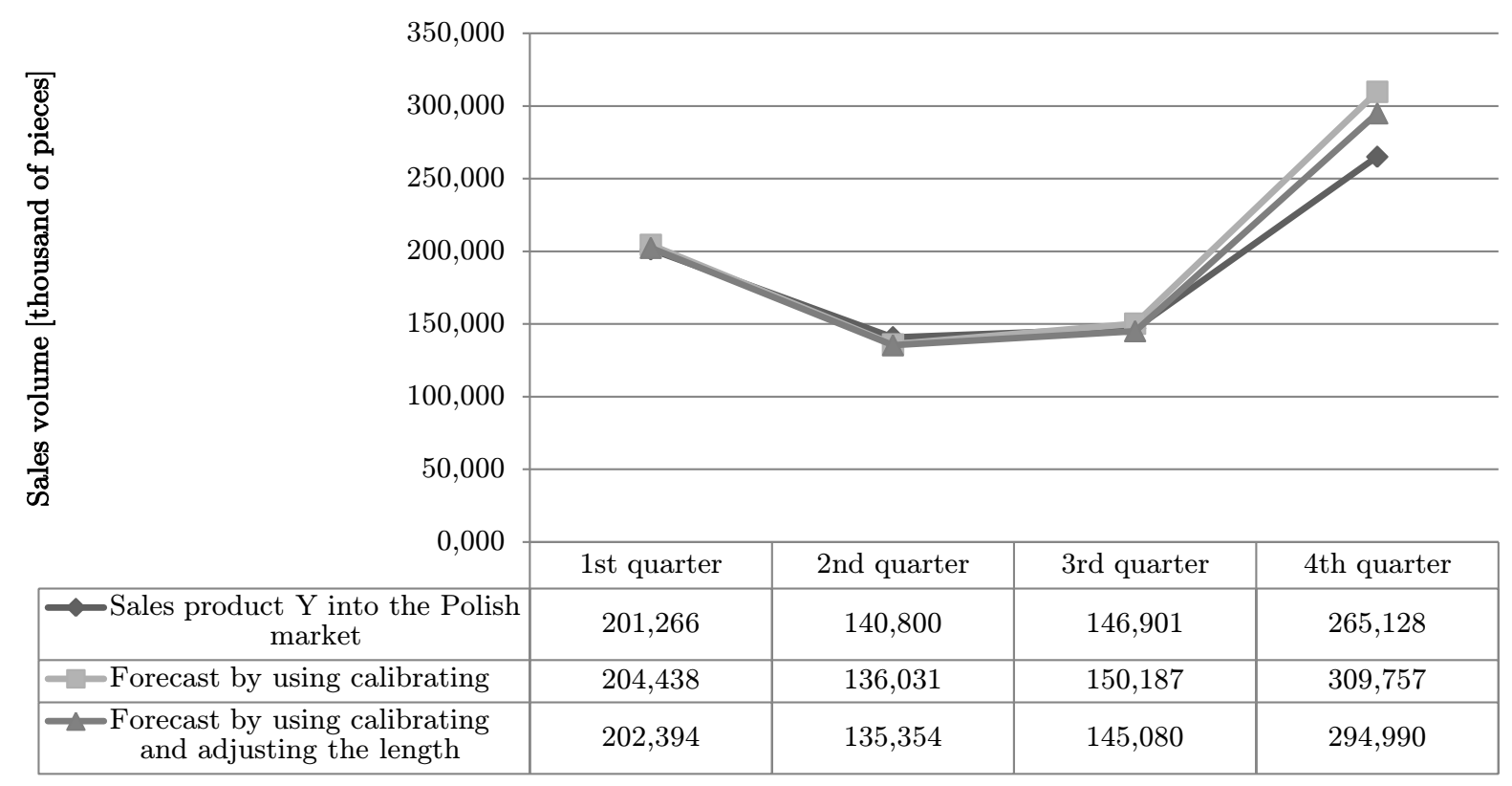

Fig. 4. Comparison of sales forecasts for product $Y$

We can observe that this procedure allows for the calculation of a forecast with a very small forecast error.

\section{CONCLUSIONS}

This research leads us to believe that the hypothesis that measures of similarity, especially function $f_{k}$, can be used to calculate sales forecasts with only a small amount of data about sales for products with short life cycles. Repeated use of the presented methodologies enabled the determination of the following forecasting stages:

1) Checking the similarity between compared products using time series representing the sales life cycles of different products.

2) Transforming the sales data of similar, but different, objects by applying the methodologies of calibrating and adjusting the length.

3) Choosing the template that becomes the basis for calculating the forecast of sales for a new product for the whole life cycle.

4) Updating the forecast by calculating a part of a sales profile after receiving more data about sales of a new product (adapting process).

The presented methodology is not a perfect method of forecasting. However, it can be used not only for products with a short life cycle, but also for telecommunication services, new technologies, textile sales, etc. This forecast method allows the derivation of results with less than a $10 \%$ forecast error.

Despite the lack of historical data about sales for a new product, forecasting for their sales becomes possible. The presented example proves the effectiveness of analogous fore-casting for products that have a life cycle not longer than two years. Statistical methods are insufficient and less accurate in predicting sales for such products. 
Having received accurate forecast data, product managers can make better decisions concerning coordination of logis-tical processes in companies.

\section{REFERENCES}

Azoury, K., 1985. Bayes solution to dynamic inventory models under unknown demand distributions. Management Science, 31(9), 1150-1160.

Burruss, J., Kuettner, D., 2002/2003. Forecasting for short-lived product: Hewlett-packard's journey. The Journal of Business Forecasting Methods \& Systems, pp. 9-14.

Brzeziński, J., 1997. Metodologia badań psychologicznych. Wydawnictwo Naukowe PWN, Warszawa.

Cieślak, M., Jasiński, R., 1979. Miara podobieństwa funkcji. Przeglad Statystyczny, z. 3/4, pp. 169-173.

Cieślak, M., Ed.), 2000. Prognozowanie gospodarcze. Metody i zastosowania. Wydawnictwo Naukowe PWN, Warszawa.

Dittmann, P., 2002. Metody prognozowania sprzedaży w przedsiębiorstwie. Wydawnictwo Akademii Ekonomicznej im. Oskara Lanego, Wrocław.

Duncan, G.T., Gorr, W.L., Szczypula, J., 2001. Forecasting analogous time series [in:] Armstrong J.S., Ed.): Principles of forecasting, pp. 195-213. Boston.

Fisher, M., Raman, A., 1996. Reducing the cost of demand uncertainty through accurate response to early sales. Operations Research, 44(1), 87-99.

Fisher,M., Raman, A., 1999. Managing short life-cycle products. Ascet, 1, 4/15.

Green, K.C., Armstrong, F.S., 2007. Structured analogies for forecasting. International Journal of Forecasting, 23(3), 365-376.

Harpaz, G., Lee, W.Y., Winkler, R.L., 1982. Optimal output decisions of a competitive firm. Management Science, 28(6), 589-602, June.

Johnson, G., Thompson, H., 1975. Optimality of myopic inventory policies for certain dependent demand processes. Management Science, 21(11), 1303-1307.

Kahn, K.B., 2002. An exploratory investigation of new product forecasting practices. The Journal of Product Innovation Management, 19, 133-143.

Kahn, K.B., 2006. New Product Forecasting: An Applied Approach. M.E. Sharpe, New York.

Kurawarwala, A. A., Matsuo, H., 1996. Forecasting and inventory management of short life-cycle products. Operations Research, 44(1), 131-150.

Lee, Y.W., Goodwin, P., Fildes, R., Nikolopoulos, K., Lawrence, M., 2007. Providing support for the use of analogies in demand forecasting tasks. International Journal of Forecasting, 23(3), 377-390.

Lin Feng-Jenq, 2005. Forecasting telecommunication new service demand by analogy method and combined forecast. Yugoslav Journal of Operations Research, 15(1), 97-107.

Lindsay, D.A., Norman, P.H., 1977. Human information processing: An introduction to psychology. Academic Press, London.

Miller, B.L., 1986. Scarf's state reduction method, flexibility, and a dependent demand inventory model. Operations Research, Vol. 34, No 1, January-February, pp. 83-90.

Nikolopoulos, K., Goodwin, P., Patelis, A., Assimakopoulos, V., 2007. Forecasting with cue information: A comparison of multiple regression with alternative forecasting approaches. European Journal of Operational Research, 180(1), 354-368.

Nowak, E. (Ed.), 1998. Prognozowanie gospodarcze. Metody, modele, zastosowania, przyklady. Agencja Wydawnicza PLACET, Warszawa.

Ray, W.D., 1982. Arima forecasting models in inventory control. Journal of Operational Research Society, 33(6), 567-574, June 1982. 
Szanduła, J., 2002. Metody analogowe w prognozowaniu spoteczno gospodarczym. PhD thesis, Department of Forecast and Economic Analyzes in Wroclaw University of Economics, Wrocław.

Wu, S.D., Aytac, B., 2007. Characterization of demand for short life-cycle technology products. Technical report, Lehigh University, Raport No. 07T-005. 